O AUTOR

A. P. Quartim de Moraes

Jornaslista, gerente editorial da Editora Senac.

\title{
MULTICULTURALISMO E IDENTIDADE: O PAPEL DOS MEIOS DE COMUNICAÇÃO E DA ESCOLA ${ }^{1}$
}

\section{Referencial importante para se pensar multiculturalismo e identidade é o descompasso entre as conquistas tecnológicas e a crescente exclusão social}

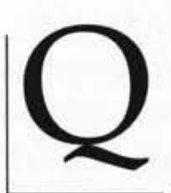

ual o papel dos meios de comunicação e da escola diante da realidade multicultural em constante e acelerado processo de transformação ? E as implicações desse processo no que diz respeito ao contraponto, se é que ele existe, multiculturalismo/identidade?

Não acredito que seja um problema grave a aparente contradição entre multiculturalismo e identidade. Não vejo o multiculturalismo, um fenômeno aparentemente hoje mais presente do que nunca em todo o mundo moderno, como uma ameaça à identidade cultural de povos, nações, grupos étni$\cos$, comunidades regionais ou qualquer outro grupamento humano - ou mesmo à identidade do próprio indivíduo.
Em função do acelerado desenvolvimento tecnológico, o mundo se tornou menor. E o multiculturalismo, que existe porque os homens são diferentes entre si, hoje tem muito mais visibilidade, além do que certamente é mais rico e variado do que no passado, muito mais multi, exatamente graças ao intenso contato entre as mais diversas culturas propiciado pelo desenvolvimento tecnológico, pelo encurtamento das distâncias culturais na aldeia global.

Acredito na humanidade como a unidade na diversidade. A unidade da condição humana na diversidade do indivíduo. Creio ser inerente a uma visão antropocêntrica do universo o princípio de que a individualidade que caracteriza o ser humano se projeta, em círculos concêntricos, nos grupamentos de vá- 
rios tipos e amplitudes em que o homem se associa, desde a família e o clã até, - do ponto de vista espacial, territorial - a urbe, a região, o país, ou - numa outra dimensão -, a partir de pressupostos étnicos, religiosos, ideológicos. Tudo, enfim, que reúna um grupamento humano em torno de traços comuns que o identificam como tal - como grupo, comunidade. E a mesma tendência natural, por instinto, e cultural, por educação, que os indivíduos têm de preservar sua identidade, se projeta nos vários grupamentos em que esses indivíduos se reúnem. É um fenômeno tão antigo quanto a história da humanidade e se constitui, certamente, num dos fatores preponderantes em sua evolução.

É óbvio que nenhum grupamento humano culturalmente identificável permanece $o$ mesmo depois de seu contato com outro. Pelo fenômeno inevitável da aculturação, algumas culturas acabam predominando sobre as outras. Influindo mais do que sendo influenciada. Mas, inevitavelmente, nesse contato até as que preponderam se modificam, se transformam, do mesmo modo que as, vamos chamar assim, menos poderosas, de algum modo conseguem preservar traços essenciais de sua identidade, só deixando mesmo de existir no caso extremo do extermínio físico de seus indivíduos.

A questão que fica em aberto, e o ideal é que seja resolvida pelo próprio grupo, é saber até que ponto, social, política, econômica e culturalmente, a permanente e inevitável influência de outras culturas é tolerável ou desejável.
Os casos extremos de tentativa de preservação quase absoluta de identidade cultural, como pretende o Taliban no Afeganistão, ou outros fundamentalismos soltos pelo mundo, devem ser debitados à conta do fanatismo religioso ou ideológico, ou são meros instrumentos de dominação - ou ainda tudo isso ao mesmo tempo. São desumanos e estão na contramão da história.

Assim, a inter-relação multiculturalismo/ identidade acaba se resolvendo por si própria. O que me parece um grande problema é a relação que escola e comunicação têm hoje com esse binômio.

\section{PROGRESSO E EXCLUSÃO}

Uma obviedade: como resultado de uma ação multicultural permanente e inevitável, que se traduz sobretudo em espetaculares conquistas tecnológicas, o mundo de hoje é muito diferente daquele de apenas um século atrás. Uma afirmação a respeito da qual há controvérsia: este, o de hoje, é um mundo melhor. A humanidade está melhor hoje do que estava 100 anos atrás.

Não me alinho, como se vê, entre os pessimistas sempre a proclamar que o mundo está muito pior hoje do que ontem, nem entre os catastrofistas a garantir que, com toda a certeza, estará pior ainda amanhã.

Basta olharmos em volta, perto de nós. Temos problemas gravíssimos no Brasil. Somos, ainda, um país subdesenvolvido. Mas, para mencionar apenas as maiores evidências, em 1900 ainda ecoava no ar por aqui o pavoroso ranger dos grilhões de uma escravatura recém-extinta. As mulheres permaneciam legalmente 
relegadas à condição de cidadãs de segunda categoria, sem direito sequer ao voto. Este, aliás, o voto, privilégio de varões qualificados, era abertamente manipulado pelas oligarquias dominantes. Direitos e garantias trabalhistas, um devaneio que demoraria ainda quase meio século para se tornar realidade.

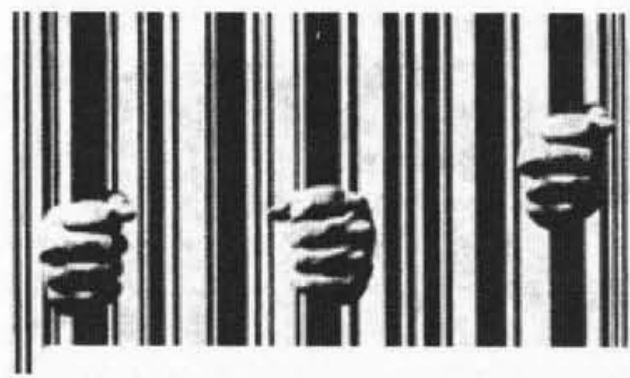

Le Monde Diplomatique, jun/1998.

$\mathrm{E}$ as conquistas tecnológicas no campo da saúde, dos transportes, das comunicações etc. Todas essas e muitas outras transformações para melhor, no Brasil e no mundo, ocorreram no lapso de 100 anos, uma pequena fração de tempo na perspectiva da história da humanidade.

De modo que não há como deixar de admitir: a humanidade tem evoluído, e muito rapidamente nas últimas décadas.

A questão que me parece central é a seguinte: o enorme descompasso entre as importantes conquistas político-sociais somadas a essa fantástica evolução tecnológica da humanidade no século XX e a tradução desse grande progresso em termos de equivalente, efetiva e universal promoção humana.

Este é o ponto: com as conquistas democráticas e os recursos tecnológicos hoje disponíveis, é inadmissível que uma parcela significativa da Humanidade ainda permaneça mergulhada em condições subumanas de vida. Uma miséria que não é novidade na trajetória humana. Mas que se torna inadmissível, repito, no momento em que fabulosos recursos de toda natureza cada vez mais se concentram nas mãos de poucos, quando deveriam estar sendo decididamente destinados a eliminar da face da Terra o estigma aviltante da exclusão social.

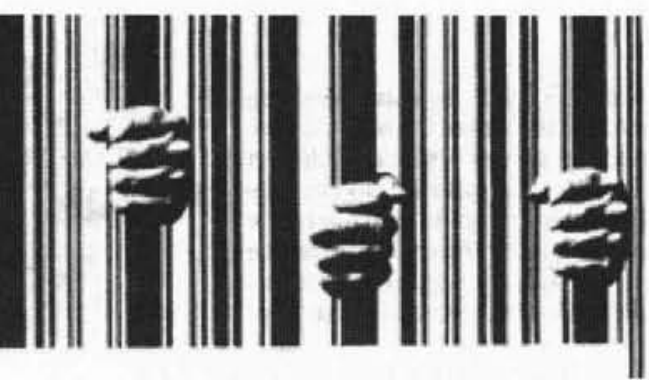

De modo que, do ponto de vista ideológico - e esta é uma postura realmente radical -, acho que a Humanidade se encontra hoje dividida em dois grandes grupos: de um lado, os que defendem, ou pelo menos admitem - geralmente sem confessá-lo - a exclusão social como um fenômeno histórica e economicamente inevitável, e por isso moralmente admissível; e de outro lado, os que entendem que o compromisso com a inclusão social é um imperativo irrenunciável da condição humana. Porque esta, a condição humana, é o traço comum que, acima de todas as diferenças étnicas, culturais, religiosas, ideológicas, nacionais, econômicas etc. etc. etc., une e identifica a cada um de nós, o habitante deste planeta que alguém insensatamente um dia batizou de homo sapiens.

Nesse ponto fundamental, acredito que não haja meio termo. Pode-se chamar esse conflito como quiser: direita versus esquerda, progressistas versus reacionários, 
Norte versus Sul, bandidos versus mocinhos. Mas é um lado ou outro. Não se pode ficar em cima do muro. Ou você acredita que o vivente que está a seu lado, ou aquele que você vê nas fotos dos livros que fizeram a fama do Sebastião Salgado ${ }^{2}$, ou você acredita que todos eles compartilham com você a condição humana e então passa a pensar e agir de modo coerente com essa convicção - ou você se desumaniza na pretensão de ser melhor ou mais digno do que o seu semelhante - por mais diferente de você que esse semelhante seja.

Não há meio termo. Ou se está de um lado, ou de outro.

\section{ESCOLA E COMUNICAÇÃO}

Onde entram nisso escola e comunicação? No fato de que tanto uma quanto outra têm sempre atrás de si, inevitavelmente, uma ideologia. E por essa razão se colocam, em última análise, diante da alternativa inescapável: estão a serviço da inclusão ou da exclusão social.

O conhecimento, o saber, sempre foi, na história da humanidade, o mais poderoso instrumento de dominação. Por extensão, a comunicação também.

Nos últimos 50 anos, a história das ciências e das mentalidades virou muitas páginas. E muito rapidamente. Já na década de 60 se tornara moda falar no advento da aldeia global, como resultado daquilo que hoje é banalmente conhecido como processo de globalização. Se, por um lado, a segunda metade do século XX viu ruir a ilusão do desenvolvimento econômico e da justiça social top-down (de cima para baixo), por outro verificou uma aparentemente paradoxal elevação da taxa de consciência daquilo que genericamente se pode chamar de questão social. Afinal, o mundo se tornou realmente uma pequena aldeia e a mesma globalização que é causa/conseqüência da internacionalização do capital, dos interesses meramente econômicos e financeiros, é responsável também pela ampla e imediata circulação das idéias - até as mais progressistas. Daí, por exemplo, o politicamente correto, essa invenção norte-americana que é magnífica demonstração da má consciência dos sobrinhos de Tio Sam diante de seus próprios preconceitos.

É muito bom, enfim, perceber que hoje, mais do que nunca, no chamado mundo civilizado, o principal fundamento da questão social, que é a consciência de si mesmo e da existência e do respeito ao outro (ou, como diriam os melhor catequizados, ao próximo), essa consciência - que podemos chamar de consciência da cidadania tem alguma possibilidade de se tornar um valor universalmente reconhecido.

É nessa perspectiva que se depositam as melhores esperanças de um futuro de maior justiça e eqüidade entre os seres humanos, e nessa transformação, certamente, a escola e a comunicação desempenham um papel central.

$\mathrm{Na}$ escola, a relativamente recente tendência de mudança do foco no ensino para

2. Fotógrafo brasileiro mundialmente conhecido pela qualidade de seu trabalho e pelo seu projeto profissional de registrar os excluídos. Há no Brasil vários de seus trabalhos publicados em livros, como por exemplo, Exodo. São Paulo: Companhia das Letras, 2000. 
o foco no aprendizado, fundada em novos conceitos como o da aprendizagem com autonomia, do aprender a aprender, acenam com a perspectiva de uma educação realmente capaz de promover o homem à plenitude de sua condição de indivíduo apto a pensar criticamente e sentir afetivamente, com o necessário equilíbrio entre a razão e a emoção, o sentimento. Isso é possível. Os meios estão aí, à nossa disposição.

$\mathrm{Na}$ comunicação, o advento de um Homem mais consciente e crítico certamente colocará as coisas em seus devidos lugares. Mas é lógico que não podemos ficar esperando que a utopia se realize.

De imediato, a questão central é a da democratização dos meios de comunicação. Para ser mais preciso, do controle democrático dos meios de comunicação.

Mais fácil falar do que fazer. É uma questão complexa e delicada, como tudo o que envolva controles na sociedade. Qualquer descuido pode descambar para o autoritarismo. Isso é sempre perigoso. Mas está claro que algo precisa ser feito para neutralizar as hegemonias que acabam colocando os meios de comunicação a serviço da exclusão social e transformando-os em ameaça - esta sim, uma ameaça a ser levada a sério - ao multiculturalismo, à identidade cultural.

Mas, também aí, mais uma vez o desenvolvimento tecnológico pode dar uma boa mãozinha. Por exemplo, o advento da TV a cabo, com a multiplicação de opções para o telespectador, em poucos anos já fez um estrago considerável na hegemonia das grandes redes, em todo o mundo. É um dado altamente positivo, um progresso, mesmo considerando que são as próprias grandes redes que dominam boa parte do espaço aberto pela TV a cabo. E na Internet - que não resolveu ainda se vai se transformar num grande shopping center ou num imenso parque de diversões - criam-se já as condições para o acirramento da saudável concorrência no mercado da informação, o que também não é uma boa notícia para as forças hegemônicas da mídia em todo o mundo.

Todas essas transformações que atingem a escola e os meios de comunicação são muito recentes. Não dá para se saber ainda nem mesmo quais são as novidades que vieram para ficar, quais as que logo serão descartadas como simples modismo.

O importante é que saibamos aproveitar esse embalo das transformações. Que o façamos com a consciência de que o maior desafio, o primeiro da lista, é tomar posição ativa no time da inserção social, que disputa uma peleja de vida ou morte para a humanidade, com o time da exclusão.

Só assim será possível reconstruir o mundo em bases verdadeiramente humanas. Só assim será possível transformar o homem em sujeito da história, e não em seu objeto. Só assim será possível, de um lado, recuperar da alienação e do egoísmo aqueles que acham que precisam excluir para viver, e de outro lado, resgatar da exclusão aqueles que também têm o direito de participar, dignamente, como protagonistas, do espetáculo da vida.

Essa é a grande missão da Escola. Esse é o grande desafio da Comunicação. 
Resumo: $\mathrm{O}$ autor discute a relação, no mundo globalizado, entre multiculturalismo e identidade. Afirma que a aparente contradição que expressam não é um problema grave. Trata-se de um fenômeno pelo qual a humanidade vem passando ao longo de sua história. Destaca, entretanto, que o acelerado desenvolvimento tecnológico e a concentração de riquezas têm traçado um quadro dramático no que diz respeito ao multiculturalismo e à identidade, à medida que têm levado grandes parcelas da população à exclusão socioeconômica e, portanto, limitado seu acesso aos bens culturais e ao conhecimento disponiveis na sociedade contemporânea. Os meios de comunicação e a escola podem, segundo a concepção do autor, desempenhar importante papel, diminuindo as distâncias entre incluídos e excluídos, bem como trabalhando no sentido da inclusão social.

Palavras-chave: multiculturalismo, identidade, exclusão, meios de comunicação, escola, diversidade cultural
(Multiculturalism and identity: the role of the media and of the school)

Abstract:The author discusses the relation there is, in a globalized world, between multiculturalism and identity. According to the author, the apparent contradiction they represent is not a serious problem. This is a phenomenon humanity has been going through throughout history, Emphasis is given, however, to the fact that the accelerated technological developments and the concentration of richness has traced a dramatic picture regarding multiculturalism and identity since it has lead major portions of the population to socioeconomic exclusion and, therefore, it has limited their access to all of the cultural goods and to the knowledge that is available in contemporaneous society. The media and the school can, according to the author's conception, have an important role in reducing distances between the included and the excluded, as well working aiming at social inclusion.

Key words: multiculturalism, identity, exclusion, media, school, cultural diversity 